\title{
The Dependence of Repulsion Tennis Ball from the Air Pressure in it
}

\author{
Dusko Bjelica' , Marija Bubanja', Jovan Gardasevic ${ }^{1}$ \\ 'University of Montenegro, Faculty for Sport and Physical Education, Niksic, Montenegro
}

\begin{abstract}
The aim of this study is to determine the elastic (reflective) properties of the tennis ball depending on the air pressure in it. The standard tennis ball was released on a flat, solid surface from a height of nine meters, three times. For a tennis ball pressure was measured based on the time and rebound of the ball after the first, second and third falls. In the first release the air in the ball was under prescribed pressure. After the first release, the pressure in the ball is reduced by the fact that the ball once is stabbed with a hollow medical needle, after the second release, the pressure in the ball is reduced further by the ball being pierced twice with a hollow medical needle. The setting of the experiment was done by filming the free fall of the prescribed tennis balls and a series of rebounds after being rejected from a solid surface. It can be concluded that the distance traveled and the total duration of four successive reflections largely depended on the internal pressure. In this study, the initial tennis ball velocity was unchanged and only internal pressures were changed. It was determined how much the rejection rate was reduced and the duration of the re-acceleration, depending on the reduction of the internal pressure. All in all, it can be concluded that the initial speed of the ball can be increased by increasing the internal pressure in the ball.
\end{abstract}

Key words: Tennis, Ball, Repulsion

\section{Uvod}

U okviru programa fizičkog razvoja, igre predstavljaju dominantnu ulogu, a među svim igrama najvažnije su igre sa loptom (Gardašević, Bjelica, i Vasiljević, 2017; Bjelica, Popović, \& Gardašević, 2016b). Sve lopte, izuzev lopte za američki fudbal su geometrijska tijela sa tendencijom da se konstruišu sa punom simetrijom. Takvom tijelu, kada se kreće po tlu ili u prirodnim fluidima može da se predvidi putanja (Bjelica, 2014). Lopte su kuglastog oblika, napumpane vazduhom i sa većim pritiskom od atmosferskog (Bjelica, 2014; Bjelica \& Gardasevic, 2018). Danas se proizvode sve vrste lopti čija se konstrukcija približava punoj simetriji, ali idealna simetrija lopte još nije postignuta (Bjelica, Popović, Gardašević, \& Krivokapić, 2016).

U svim sportovima se uglavnom vodi bitka za prostornu ili vremensku prednost. To su dvije najvažnije komponente $u$ igrama sa loptom, pa tako i u tenisu. Da bi bio dobar sportista, on bi morao da ima visoko razvijeni dinamički streotip za sva- ki pokret, odlučujući u datom sportu (Bjelica, 2005; Bjelica, 2014; Bjelica i Fratrić, 2011). Tenis je jedna od najljepših, ali i najsloženijih sportskih igara koja pripada kategoriji kompleksnih sportskih aktivnosti, acikličnih kretnih struktura sportista u uslovima sportskog nadmetanja između pojedinaca ili ekipa (Milanović, 2010). Tenis je okarakterisan kao „igra otvorenih vještina”, jer igrač nikada ne ponovi udarac na isti način, svako odigravanje loptice je drugačije i svaka je situacija u igri specifična (Filipčič, 2007).U dobrom meču, svaki igrač ima puno elementarnih mišićnih kontrakcija na terenu, praveći niz složenih pokreta (Bjelica, Popović, \& Gardašević, 2016a; Bjelica, Popović, Tanase, \& Gardašević, 2017) koje karakteriše veliki broj cikličnih (Gardašević, Vasiljević, i Bojanić, 2015; Bjelica, Popović, i Gardašević, 2016c; Bjelica, Popović, i Gardašević, 2016d, Sermaxhaj, Popović, Bjelica, Gardašević, i Arifi, 2017; Gardašević, Bjelica, \& Vasiljević, 2017a; Gardašević, Bjelica, \& Vasiljević, 2017b) i acikličnih kretanja (Gardašević, Bjelica, Milašinović, i Vasiljević, 2016). Lopta je mašina, čijih svojstava

Correspondence:

Montenegro M. Bubanja

Gport University of Montenegro, Faculty for Sport and Physical Education, Narodne omladine bb, 81400 Niksic, Montenegro E-Mail: marijabubanja@ymail.com 
svaki igrač mora biti u potpunosti svjestan (Bjelica, 2008). Ovo je glavni razlog zašto svaki igrač mora biti potpuno svjestan prirode elastičnih osobina teniske lopte.

Cilj ovog istraživanja je odrediti elastične (odbojne) osobine teniske lopte u zavisnosti od pritiska vazduha u njoj, koji su u osnovi pod kinematičkim istraživanjima.

\section{Metod}

Istraživanje sprovedeno u ovoj studiji prvenstveno se odnosi na standardnu tenisku loptu sa sledećim performansama (Tabela 1).

Tabela 1. Dimenzije teniske lopte

\begin{tabular}{cccccc}
\hline $\begin{array}{c}\text { Masa } \\
(\mathbf{k g})\end{array}$ & $\begin{array}{c}\text { Poluprečnik } \\
(\mathbf{m})\end{array}$ & $\begin{array}{c}\text { Obim } \\
(\mathbf{m})\end{array}$ & $\begin{array}{c}\text { Poprečni presjek } \\
(\mathbf{m})\end{array}$ & $\begin{array}{c}\text { Površina } \\
(\mathbf{m})\end{array}$ & $\begin{array}{c}\text { Zapremina } \\
(\mathbf{m} \mathbf{3})\end{array}$ \\
\hline 0.5759 & 0.0325 & 0.205 & 0.00332 & 0.01327 & 0.000144 \\
\hline
\end{tabular}

Lopta za tenis puštana je na ravnu čvrstu podlogu sa visine od devet metara, tri puta. Za tenisku loptu je mjeren pritisak na osnovu vremena i odskoka lopte poslije prvog, drugog i trećeg pada. U prvom puštanju vazduh u lopti je bio pod propisanim pritiskom. Poslije prvog puštanja pritisak u lopti je smanjen tako što je lopta jedanput probodena šupljom medicinskom iglom, nakon drugog puštanja pritisak u lopti je smanjen dodatno tako što je lopta probodena dvaput sa šupljom medicinskom iglom.

Kalibriranim mjernim pritiskom izmjereni su unutrašnji pritisci. Postavka eksperimenta bila je realizovana kino-snimanjem slobodnog pada i serije odskoka nakon odbijanja od čvrste podloge propisane lopte za tenis. Snimanje je vršeno profesionalnom digitalnom raid-kinokamerom JVC GYHM750E, sa 50 snimaka u sekundi i ekspozicijom sec/100. U toku snimanja kamera je bila potpuno imobilisana. U projek- ciji kretanja lopte bili su izmjereni (u metrima) markeri, radi određivanja razmjere $(\mathrm{R})$ između veličina na ekranu i realnih veličina $\left(\mathrm{R}=\right.$ veličine $\frac{\text { prirodne }}{\text { ekranske })}$

Prilikom ovog istraživanja površina sudara se određivala prenosnim kontrastnim bojama lopte i podloge prije sudara sa tlom i mjerenje površina otisaka na lopti i podlozi nakon odskoka. Vrijeme trajanja kretanja mjereno je u sekundama, tj. svakih pedeset pozicija trajalo je jednu sekundu odnosno vrijeme trajanja između dviju susjednih pozicija trajalo je sec/50. U obradu uzete su pozicije pada lopte i četiri odskoka.

\section{Rezultati}

U Tabeli 2 nalazi se globalni prikaz prostornovremenskih parametara repulzije teniske lopte sa punom simetrijom u zavisnosti od pritiska vazduha u lopti.

Tabela 2. Prostornovremenski parametri odbijanja teniske lopte sa različitim vazdušnim pritiscima

\begin{tabular}{clccc}
\hline & & $\begin{array}{c}\text { A } \\
\text { Standard }\end{array}$ & $\begin{array}{c}\text { B } \\
\text { 1 ubod }\end{array}$ & $\begin{array}{c}\text { C } \\
\text { uboda }\end{array}$ \\
\hline h1 & Visina slobodnog pada (m) & 9.00 & 9.00 & 9.00 \\
t1 & Vrijeme trajanja prvog padanja (sec) & 1.12 & 1.1 & 1.08 \\
t2 & Vrijeme trajanja prvog penjana (sec) & 0.66 & 0.58 & 0.60 \\
h2 & Visina prvog odskoka (m) & 3.32 & 3.02 & 3.02 \\
t3 & Vrijeme trajanja drugog padanja (sec) & 0.64 & 0.68 & 0.66 \\
t4 & Vrijeme trajanja drugog penjana (sec) & 0.64 & 0.38 & 0.44 \\
h3 & Visina drugog odskoka (m) & 1.72 & 1.55 & 1.47 \\
t5 & Vijeme trajanja trećeg padanja (m) & 0.48 & 0.50 & 0.40 \\
t6 & Vrijeme trajanja trećeg penjana (sec) & 0.32 & 0.32 & 0.30 \\
h4 & Visina trećeg odskoka (m) & 0.97 & 0.88 & 0.84 \\
t7 & Vrijeme trajanja četvrtog padanja (sec) & 0.36 & 0.30 & 0.32 \\
t8 & Vrijeme trajanja četvrtog penjana (sec) & 0.26 & 0.22 & 0.24 \\
h4 & Visina četvrtog odskoka (m) (sec) & 0.55 & 0.50 & 0.50 \\
\hline
\end{tabular}

U prvoj fazi, Dijagram 1 pokazuje tenisku loptu sa prostornovremenskim parametrima u prva četiri odbijanja od čvrste podloge, kada je standardan pritisak vazduha u njoj. U vertikalnom položaju postoje kulminacijske tačke svakog odbijanja lopte od površine, mjereno u metrima, a u horizontalnom položaju se dužina svakog odbijanja od površine prikazuje u sekundama.

Dijagram 2 pokazuje tenisku loptu sa prostornovremenskim parametrima u prva četiri odbijanja od čvrste podloge, kada je standardan pritisak vazduha smanjen u njoj, posle jednog ubadanja iglom.

Dijagram 3 pokazuje tenisku loptu sa prostornovremenskim parametrima u prva četiri odbijanja od čvrste podloge, kada je standardan pritisak vazduha dodatno smanjen u njoj, posle dva ubadanja iglom.

U drugoj fazi izvršena je interpolacija dijagrama kulminacionih tačaka pojedinačnih odskoka u funkciji vremena. Dijagram 4 prikazuje loptu sa standardnim pritiskom u njoj.

Dijagram 5 je interpolirani dijagram kulminacionih tačaka pojedinačnih odskoka u funkciji vremena lopte sa smanjenim pritiskom u njoj, nakon jednog uboda iglom.

Interpolirani dijagram kulminacionih tačaka pojedinačnih odskoka u funkciji vremena lopte sa dodatno smanjenim pritiskom u njoj, nakon dva uboda iglom, prikazan je na Dijagramu 6.

U trećoj fazi prikazan je dijagram kulminacionih tačaka za tenisku loptu. 


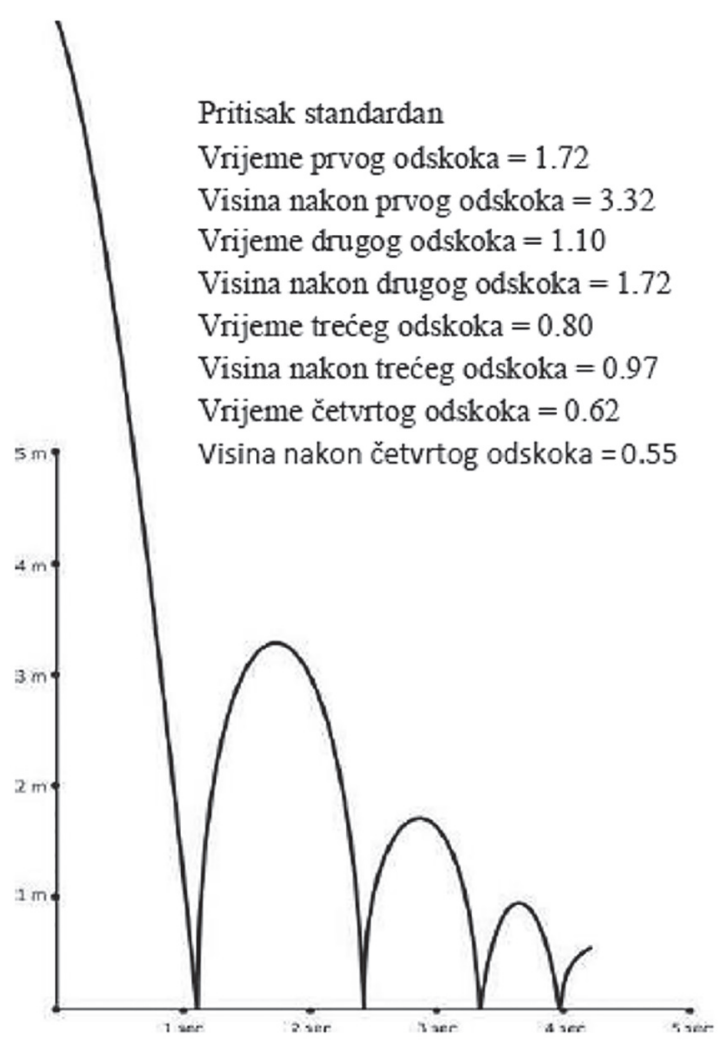

Dijagram 1. Vrijeme i visina odskoka (pritisak standardan)

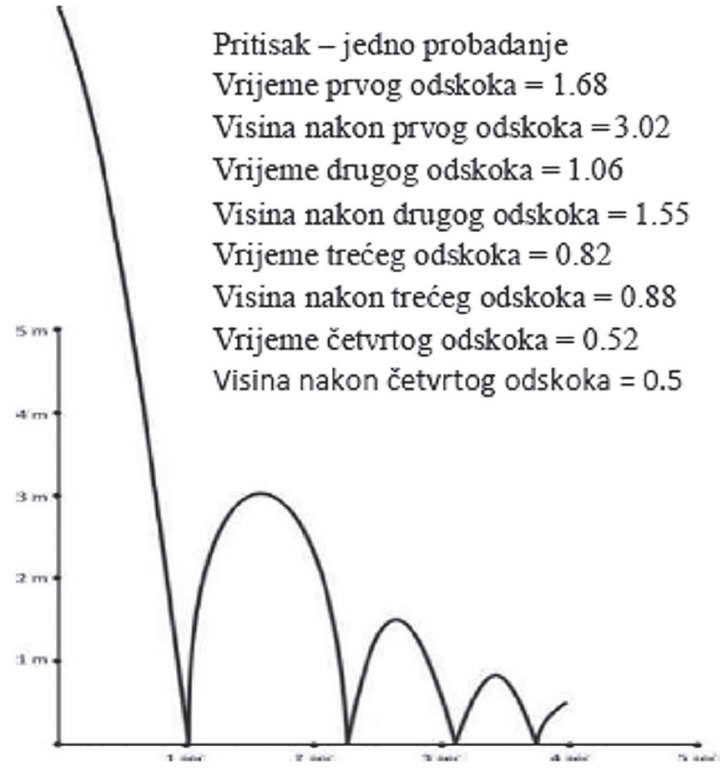

Dijagram 2. Vrijeme i visina odskoka (pritisak-jedno probadanje)

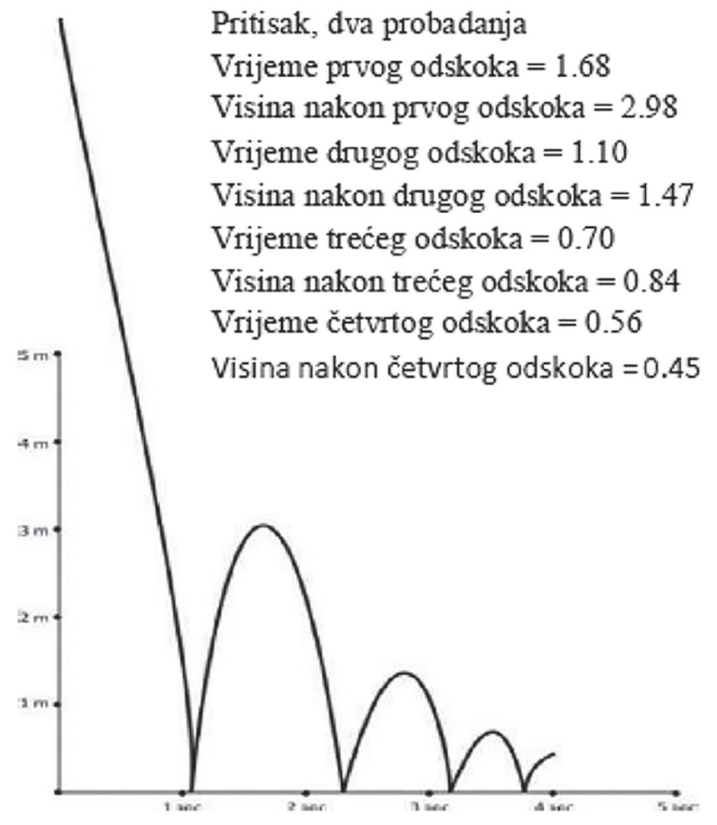

Dijagram 3. Vrijeme i visina odskoka (pritisak- dva probadanja)

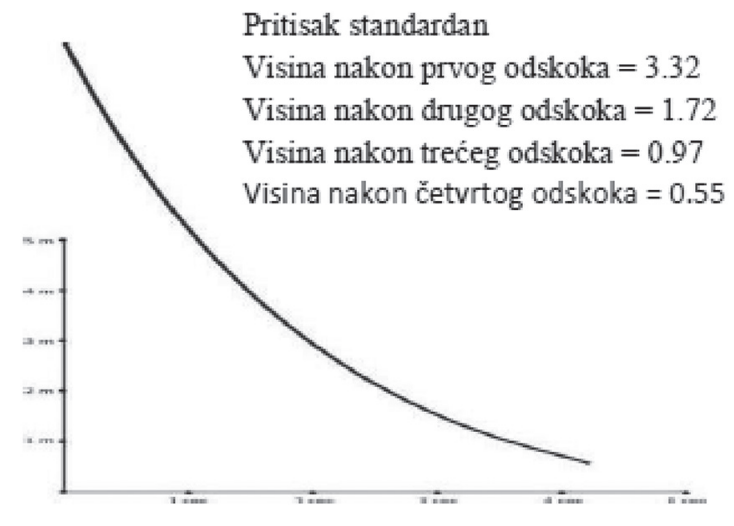

Dijagram 4. Visina odskoka (pritisak standardan) 


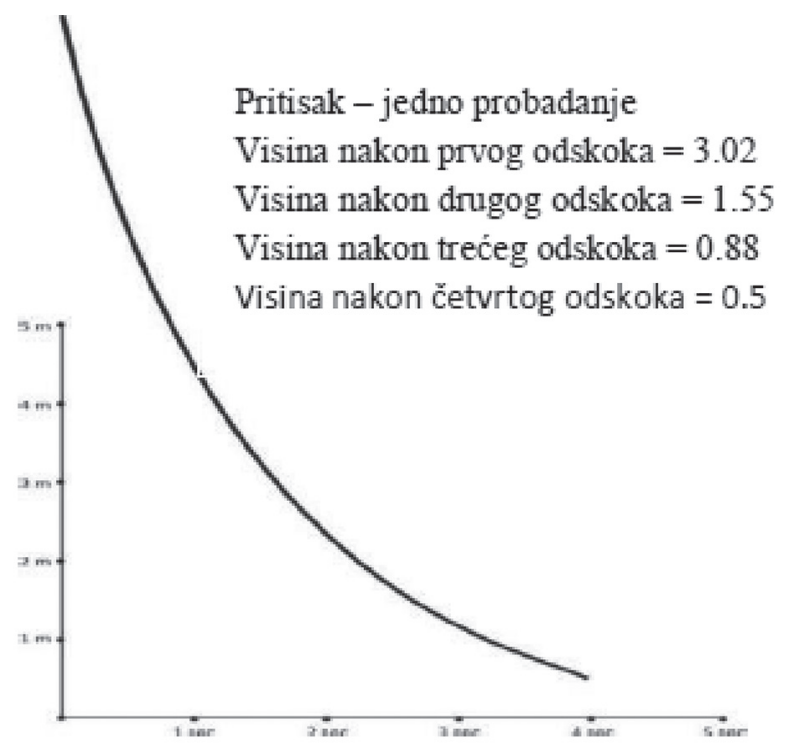

Dijagram 5. Visina odskoka (pritisak-jedno probadanje)

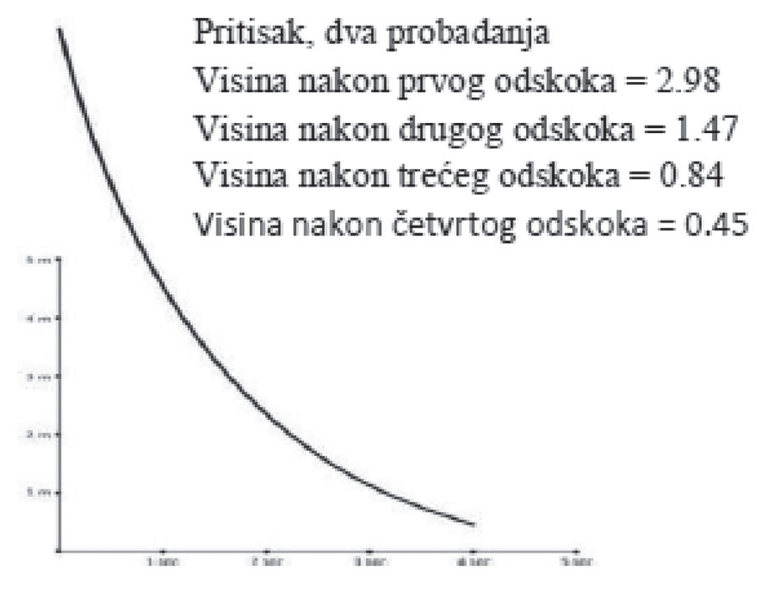

Dijagram 6. Visina odskoka (pritisak-dva probadanja)

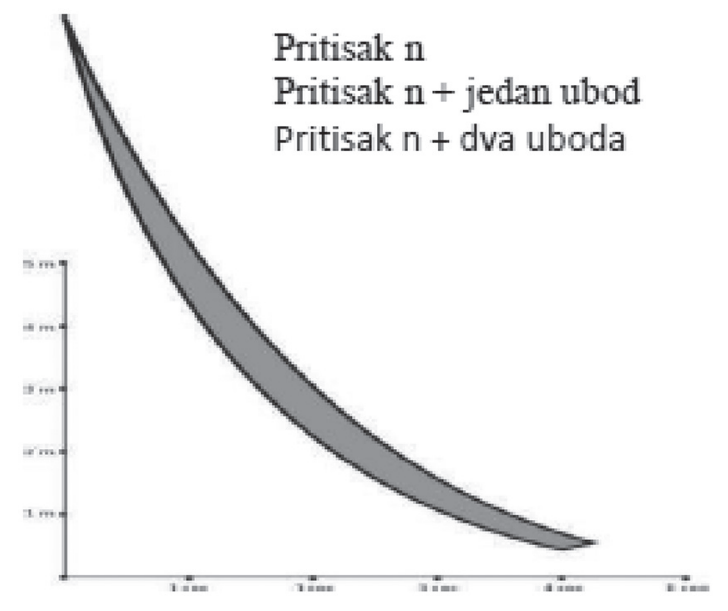

Dijagram 7. Kulminacione tačke teniske lopte

U četvrtoj fazi, u Tabelama 3, 4 i 5 prikazani su indeksi ukupnog vremena trajanja i pređenog puta za tenisku loptu za četiri odskoka i tri vrijednosti unutrašnjeg pritiska, kao i pridruženi Dijagrami 8, 9 i 10 za svaku vrijednost unutarašnjeg pritiska.

Tabela 3. Indeks ukupnog vremena trajanja i pređenog puta

\begin{tabular}{lccc}
\hline \multicolumn{1}{c}{ Teniska lopta } & $\begin{array}{c}\text { Pređeni } \\
\text { put }(\mathbf{m})\end{array}$ & $\begin{array}{c}\text { Vrijeme } \\
\text { trajanja (sec) }\end{array}$ & $\begin{array}{c}\text { Indeks = } \\
\text { put /vrijeme }\end{array}$ \\
\hline Nakon prvog odskoka & 12.32 & 1.72 & 7.163 \\
Nakon drugog odskoka & 14.04 & 2.28 & 4.979 \\
Nakon trećeg odskoka & 15.01 & 3.62 & 4.164 \\
Nakon četvrtog odskoka & 15.56 & 4.22 & 3.687 \\
\hline
\end{tabular}

Tabela 4. Indeks ukupnog vremena trajanja i pređenog puta nakon jednog probadanja

\begin{tabular}{lccc}
\hline $\begin{array}{c}\text { Teniska lopta } \\
\text { Jedno probadanje }\end{array}$ & $\begin{array}{c}\text { Pređeni } \\
\text { put }(\mathbf{m})\end{array}$ & $\begin{array}{c}\text { Vrijeme } \\
\text { trajanja (sec) }\end{array}$ & $\begin{array}{c}\text { Indeks }= \\
\text { put /vrijeme }\end{array}$ \\
\hline Nakon prvog odskoka & 12.02 & 1.68 & 7.155 \\
Nakon drugog odskoka & 13.57 & 2.74 & 4.953 \\
Nakon trećeg odskoka & 14.45 & 3.56 & 4.059 \\
Nakon četvrtog odskoka & 14.95 & 4.08 & 3.664 \\
\hline
\end{tabular}


Tabela 5. Indeks ukupnog vremena trajanja i pređenog puta nakon dva probadanja

\begin{tabular}{lccc}
\hline $\begin{array}{c}\text { Teniska lopta } \\
\text { Dva probadanja }\end{array}$ & $\begin{array}{c}\text { Pređeni } \\
\text { put }(\mathbf{m})\end{array}$ & $\begin{array}{c}\text { Vrijeme } \\
\text { trajanja (sec) }\end{array}$ & $\begin{array}{c}\text { Indeks }= \\
\text { put /vrijeme }\end{array}$ \\
\hline Nakon prvog odskoka & 12.02 & 1.68 & 7.155 \\
Nakon drugog odskoka & 13.49 & 2.78 & 4.853 \\
Nakon trećeg odskoka & 14.33 & 3.34 & 4.118 \\
Nakon četvrtog odskoka & 14.74 & 4.04 & 3.649 \\
\hline
\end{tabular}

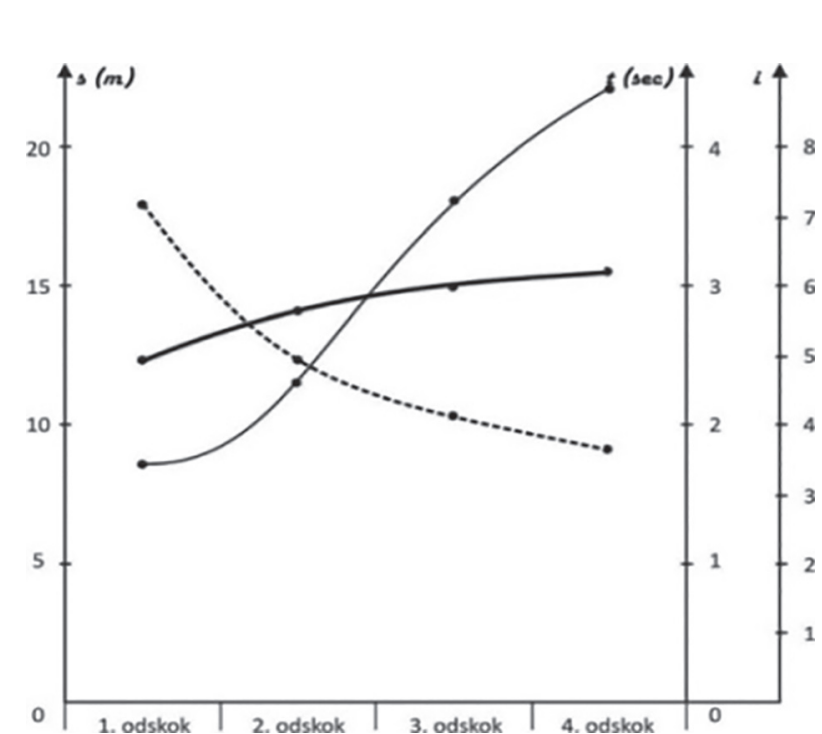

Legenda: Tanja linija: ukupno vrijeme trajanja (t); Deblja linija: ukupno pređeni put (s); Isprekidana linija: indeks $=\mathrm{s} / \mathrm{t}$.

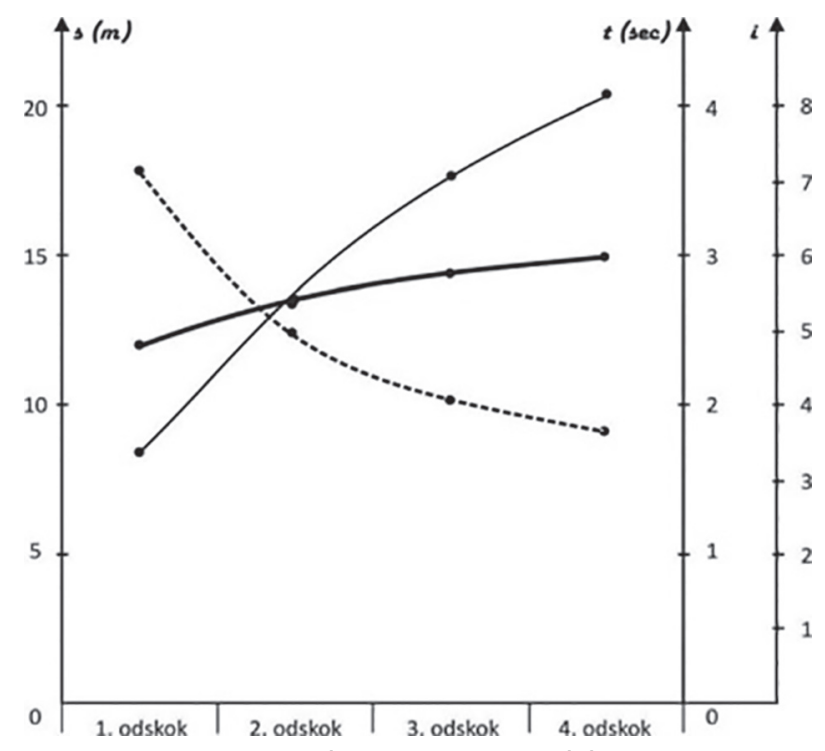

Dijagram 9. Ukupno trajanje i udaljenost (pritisak-jedan ubod)

Dijagram 8. Ukupno trajanje i udaljenost (pritisak standardan)

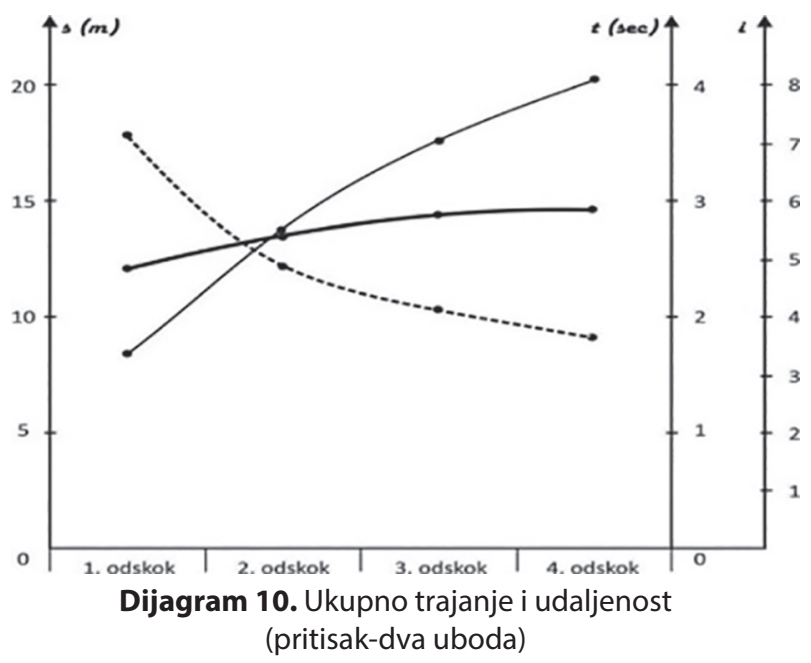

U petoj fazi izračunati su koeficijenti odbijanja teniske lopte, za svaki pritisak, za svako vrijeme trajanja i za svaku postignutu visinu (Tabela 6).

Tabela 6. Koeficijent repulzije

\begin{tabular}{lccccc}
\hline Pritisak $_{\text {atm }}$ & $\begin{array}{c}\text { Nakon prvog } \\
\text { odskoka }\end{array}$ & $\begin{array}{c}\text { Nakon drugog } \\
\text { odskoka }\end{array}$ & $\begin{array}{c}\text { Nakon trećeg } \\
\text { odskoka }\end{array}$ & $\begin{array}{c}\text { Nakon četvrtog } \\
\text { odskoka }\end{array}$ & $\begin{array}{c}\text { Prosječne } \\
\text { vrijednosti }\end{array}$ \\
\hline Standardan & 0.61 & 0.72 & 0.75 & 0.73 & 0.71 \\
1 ubod & 0.58 & 0.72 & 0.75 & 0.75 & 0.70 \\
2 uboda & 0.58 & 0.70 & 0.76 & 0.73 & 0.69 \\
\hline
\end{tabular}


Utvrđeno je da se kod teniske lopte težište i težište sabijenog vazduha $u$ ne nalaze $u$ istoj tački. Koliko god puta da se lopta nakon puštanja kretala vertikalno u slobodnom padu, nije imala vertikalan odskok od četiri sukcesivna odskakanja. Prisutnost asimetrije lopte i posljedice te asimetrije u velikoj mjeri su negativno uticale na određivanje visine kulminacionih tačaka. Da bi se mogle određivati neke zakonitosti kod repulzije teniske lopte, neophodno je odrediti dvije veličine. Prostornu, odnosno visinu kulminacione tačke težišta lopte svakog odskoka s jedne, i vremensku, odnosno trenutak odskoka, s druge strane. Sudar elastičnih tijela se odvija u dvije faze. U prvoj fazi suština sudara tijela je komprimovana, i ova faza se naziva period sabijanja ili kompresije, zbog elastičnih svojstava supstanci u sudaru, nakon kompresije se odvija druga faza sudara, koja se naziva period povratka u prethodno stanje ili restituciju (Bjelica i sar., 2016).

\section{Diskusija}

Utvrđeno je da se kod teniske lopte težište i težište sabijenog vazduha $u$ ne nalaze $u$ istoj tački. Koliko god puta da se lopta nakon puštanja kretala vertikalno u slobodnom padu, nije imala vertikalan odskok od četiri sukcesivna odskakanja. Prisutnost asimetrije lopte i posljedice te asimetrijeuvelikoj mjeri su negativno uticale na određivanje visine kulminacionih tačaka. Da bi se mogle određivati neke zakonitosti kod repulzije teniske lopte, neophodno je odrediti dvije veličine. Prostornu, odnosno visinu kulminacione tačke težišta lopte svakog odskoka s jedne, i vremensku, odnosno trenutak odskoka, s druge strane. Sudar elastičnih tijela se odvija u dvije faze. U prvoj fazi suština sudara tijela je komprimovana, i ova faza se naziva period sabijanja ili kompresije, zbog elastičnih svojstava supstanci u sudaru, nakon kompresije se odvija druga faza sudara, koja se naziva period povratka u prethodno stanje ili restituciju (Bjelica i sar., 2016).

Indeks otpora vazduha lopte ukazuje na razlike otpora vazduha, zavisno od preformansi lopte. Činjenica da je najmanji indeks otpora vazduha kod lopte za tenis praktično potvrđuje da je, pored veličine poprečnog presjeka, masa tijela značajan faktor u stvaranju otpora vazduha. Posmatrajući zbir teniske lopte od trenutka ispuštanja pa do kulminacione tačke četvrtog odskoka kao i trajanje odskakanja lopte od početka slobodnog pada pa do kulminacione tačke četvrtog odskoka, može se zaključiti da i pređeni put i ukupno trajanje četiri sukcesivna odskakanja najviše zavise od unutrašnjeg pritiska. Visina kulminacionih tačaka teniske lopte za sva četiri odskoka, od kojih su skoro sve uzete u obzir prilikom zaključivanja, su metrijske vrijednosti, koje su u ovom eksperimentu najmanje nepouzdane. Stepen odstupanja od idealne vrijednosti je skoro zanemarljiv pa se na osnovu dobijenih visinskih vrijednosti kulminacionih tačaka može pouzdano zaključivati. Nakon izračunavanja koeficijenata repulzije za tenisku loptu, za svaki pritisak i za svaki odskok, utvrđeno je da se koeficijent repulzije kreće oko 0.7. U većini sportova početna brzina lopte je dominantan faktor. Od početne brzine lopte u velikoj mjeri zavisi uspješno ostavrivanje kako taktičkih kombinacija tako i brzih i preciznih udaraca po lopti. U ovom istarživanju početna brzina teniske lopte je bila nepromijenjena a mijenjali su se samo unutrašnji pritisci. Generalno se može zaključiti da se početna brzina kretanja lopte može povećati samo na dva načina: povećanjem unutrašnjeg pritiska u lopti i jačim udarcem po lopti (impuls sile).

\section{Acknowledgements}

There are no acknowledgements.

\section{Conflict of Interest}

The authors declare that there are no conflicts of interest.

Received: 15 September 2018 | Accepted: 18 October 2018 | Published: 29 October 2018

\section{References}

Bjelica, D. (2005). Sistematizacija sportskih disciplina i sportski trening. Podgorica: Crnogorska sportska akademija.

Bjelica, D. (2008). Sportski trening. Nikšić: Fakultet za sport i fizičko vaspitanje.

Bjelica, D. i Fratrić, F. (2011). Sportski trening: teorija, metodika i dijagnostika. Nikšić: Fakultet za sport i fizičko vaspitanje.

Bjelica, D. (2014). Repulzija sportskih lopti naučna studija. Podgorica: Crnogorska sportska akademija i Univerzitet Crne Gore.

Bjelica, D., Popović, S., Gardašević, J., \& Krivokapić, D. (2016). Dependence of Football Repulsion on the Pressure Within This Sport. Journal of Physical Education and Sport, 16(2), 452-8.

Bjelica, D., Popović, S., \& Gardašević, J. (2016a). Dependence of basketball repulsion on the pressure within this sport. Journal of Physical Education and Sport, 16(1), 125-31.

Bjelica, D., Popović, S., i Gardašević, J. (2016b). Modeli fizičke pripreme vrhunskih sportaša i doziranje opterećenja. Zbornik radova 14.godišnje međunarodne konferencije "Kondicijska priprema sportaša” (185-189), Zagreb: Udruga kondicijskih trenera Hrvatske.

Bjelica, D., Popović, S., i Gardašević, J. (2016c). Opći principi planiranja i programiranja fizičkih priprema sportaša. Zbornik radova 14.godišnje međunarodne konferencije "Kondicijska priprema sportaša" (190-192), Zagreb: Udruga kondicijskih trenera Hrvatske.

Bjelica, D., Popović, S., \& Gardašević, J. (2016d). Pressure dependence of handball repulsion within this sport. Journal of Physical Education and Sport, 16(2), 1078-83.

Bjelica, D., Popović, S., Tanase, G.D., \& Gardašević, J. (2017). Dependence of female ball in handball repulsion on the pressure within this sport. Acta Kinesiologica, 11(1), 67-72.

Bjelica, D. \& Gardašević, J. (2018). Volleyball elastic properties depending on ball pressure. Sport Science, 11(1), 45-51.

Filipčič, A. (2007). Kineziološka analiza tenisa - interni materijal za studente. Zagreb: Kineziološki fakultet.

Gardašević, J., Vasiljević, I., \& Bojanić, D. (2015). Six-week preparation period and its effects on coordination transformation with football players under 16. Book of Abstracts 11th InternationalScientific Conference Management, Sport, Olympism (36), Beograd: Fakultet za menadžment u sportu, Alfa univerzitet.

Gardašević, J., Bjelica, D., Milašinović, R. \& Vasiljević, I. (2016). The Effects of the Training in the Preparation Period on the Repetitive Strength Transformation with Cadet Level Football Players. Sport Mont, 14(2), 31-3.

Gardašević, J., Bjelica, D., \& Vasiljević, I. (2016a). Six-Week Preparation Period and its Effects on Transformation Movement Speed with Football Players Under 16. Sport Mont, 14(1), 13-6.

Gardašević, J., Bjelica, D., \& Vasiljević, I. (2016b). The Effects of the Training in the Preparation Period on the Repetitive Strength Transformation with Cadet Level Football Players. Book of Abstracts of the 13th International Scientific Conference on Transformation Processes in Sport "Sport Performance" (43), Podgorica: Montenegrin Sports Academy.

Gardašević, J., Bjelica, D., \& Vasiljević, I. (2017a). The strength of kicking the ball after preparation period with U15 football players. Book of Abstracts of the 14th International Scientific Conference on Transformation Processes in Sport "Sport Performance" (65-66), Podgorica: Montenegrin Sports Academy.

Gardašević, J., Bjelica, D., \& Vasiljević, I. (2017b). The Strength of Kicking the Ball after Preparation Period with U15 Football Players. Sport Mont, 15(2), 39-42.

Milanović, D. (2010). Teorija i metodika treninga. Zagreb: Kineziološki fakultet. Sermaxhaj, S., Popović, S., Bjelica, D., Gardašević, J., \& Arifi, F. (2017). Effect of recuperation with static stretching in isokinetic force of young football players. Journal of Physical Education and Sport, 17(3), 1948-53. doi: 10.7752/jpes.2017.03191. 